\title{
ON ALKALINE WATERS FROM THE CHALK.
}

By W. W. Fisher, M.A.

(Read at the Meeting, May 1, 1901.)

THE standards of purity for natural waters are necessarily based upon the ascertained composition of unpolluted samples, which will exhibit various differences according to their origin and the geological formations from which they are obtained. The extent to which waters are rendered as "hard" or "soft" depends roughly upon the quantities of calcium or magnesium compounds taken up by them, and we expect water-supplies from limestones or chalk to be hard, while those from sandstones (with some exceptions), shales, and igneous rocks, are as a rule soft in character.

Attention has, however, been repeatedly drawn to the fact that waters from deep wells in chalk in London and other places where the chalk is covered by the London clay and tertiary beds are entirely different in character from the waters obtained either from natural springs or deep wells in chalk districts where there is no such covering of impervious deposits.

The composition of a few typical chalk waters of the ordinary kind is shown in Table I., from which it appears that such waters contain from 20 to 30 grains per gallon of dissolved solid constituents. These are chiefly carbonate of lime, with a little magnesia, with small quantities of alkaline chlorides and sulphates. These waters are always hard to an extent proportional to the lime and magnesia in solution.

On the other hand, the waters obtained from the chalk beneath the London clay contain only mere traces of lime and magnesia as carbonates, while considerable quantities of alkaline salts, mainly consisting of sodium chloride, sulphate, and carbonate, are present, and these waters, consequently, are soft and alkaline.

In Table II. are given some examples of waters of this type derived from various localities, ranging from near Reading in Berkshire to Chelmsford in Essex, and in some of these waters the excess of saline constituents is very marked. The Essex sample contains $35 \cdot 7$ grains per gallon of common salt, the total solids being $74 \cdot 8$, with 7.3 grains of anhydrous sodium sulphate and a substantial amount of sodium carbonate; while the Wokingham water with 66 grains of total solids, contains $41 \cdot 2$ grains of common salt, with sodium sulphate and carbonate in distinct but smaller proportion. The water from Clewer, near Windsor, is similar in character. Many of the waters, it will be noticed, contain traces of free ammonia, but the proportion of nitrates is always small. 
THE ANALYST.

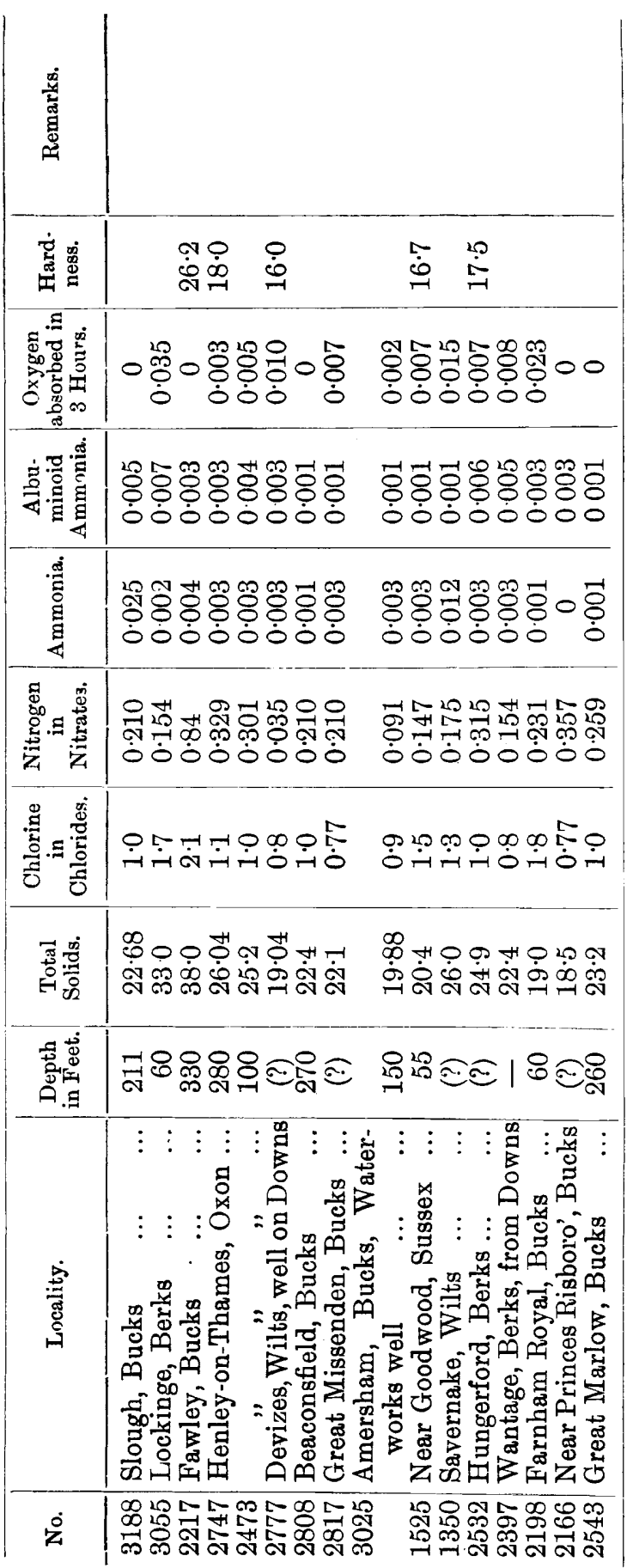

\begin{tabular}{|c|c|c|c|c|c|}
\hline 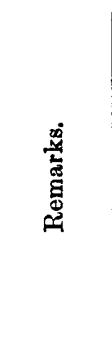 & 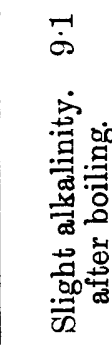 & 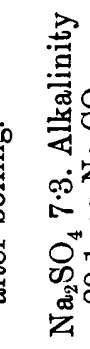 & 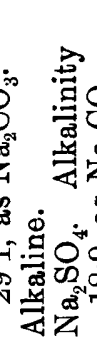 & 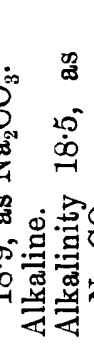 & 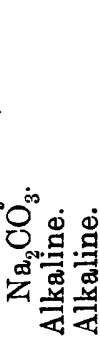 \\
\hline $\begin{array}{l}\text { 离离 } \\
\text { 总 }\end{array}$ & 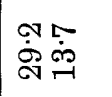 & $\dot{g}^{\varphi} \stackrel{20}{\sim}$ & \) & 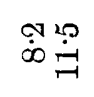 & 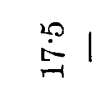 \\
\hline 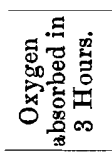 & 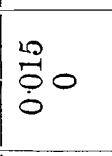 & 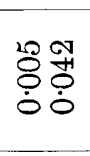 & 응ㅇํㅇ & 응영 & ○ㅇํㅇ \\
\hline 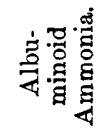 & 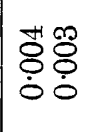 & 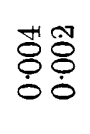 & $\begin{array}{l}200 \\
\text { 잉 } \\
\dot{0} 0\end{array}$ & 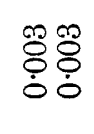 & \%̊ \\
\hline 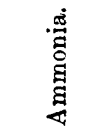 & 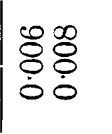 & 겅ㅇํㅇ & $\begin{array}{l}20 \% \\
\text { ơं } \\
0 \\
0\end{array}$ & 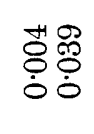 & 당ㅇํㅇ \\
\hline 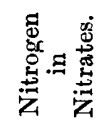 & $\begin{array}{l}20+1 \\
00 \\
00\end{array}$ & 풍ㅇㅇㅇ & & 車电 & \\
\hline 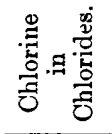 & $\stackrel{\leftrightarrow}{\dot{H}} \overrightarrow{\dot{\mu}}$ & $\stackrel{\varphi}{\dot{\sigma}} \dot{\vec{\sigma}}$ & $\begin{array}{l}9 \vec{y} \\
\vec{\forall}\end{array}$ & 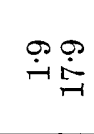 & $\stackrel{P}{\dot{\sim}} \dot{\sim}$ \\
\hline 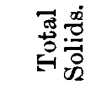 & 号星 & 吕 & $\begin{array}{l}0 \\
\dot{8}\end{array}$ & 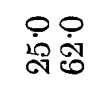 & $\begin{array}{l}\infty \\
\infty \\
\infty\end{array}$ \\
\hline 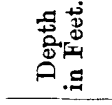 & 팡요 & ฌ্ণి & 央串 & 온유 & 8 \\
\hline 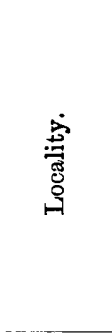 & 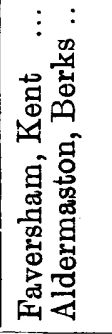 & 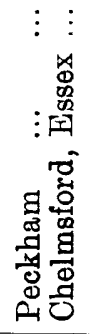 & 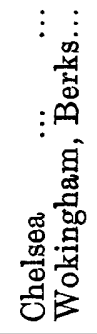 & 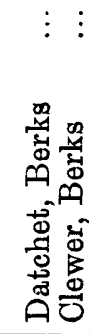 & 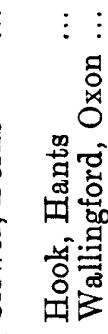 \\
\hline $\bar{z}$ & 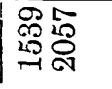 & 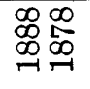 & 萧占 & 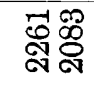 & 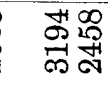 \\
\hline
\end{tabular}


Numerous wells have been sunk into the chalk below London, and careful analyses have been made in some cases of the waters obtained, and on this account the Government wells near Trafalgar Square, another at the Royal Mint, and the deep well at Guy's Hospital, are of special interest as affording an opportunity of learning whether any changes in salinity have taken place over a period of more than fifty years. After application to H.M. Office of Works, by the kindness of Mr. Westcott, Engineer-in-charge, I was able to get a sample of the water, which on analysis yielded the results given in Table III., in which also the results of former analyses are embodied.

From these results the approximate quantities of the dissolved constituents are calculated as follows :

\section{Trafalgar Square Well-water.}

Composition in Parts per 100,000 .

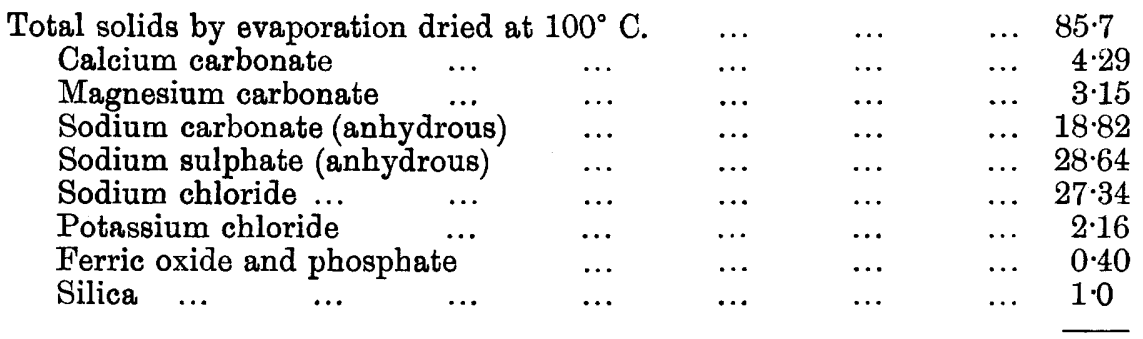

Total $\quad \ldots \quad \ldots \quad \ldots 85 \cdot 80$

A comparison of the water in 1900 with the earlier samples of 1846 and 1848 shows, as regards the total saline constituents, a diminution, but since 1857 there is no substantial change in the amount-during forty-four years. It will be seen, also, that the chlorine, sulphuric acid, lime and magnesia have undergone no important alteration for upwards of fifty years ; there is a striking change in the potash between 1848 and 1857 , but since that time the alkalies are practically constant in quantity.

These facts are very significant, and of great interest as indicating the permanent character of the conditions affecting the supply. Although, as will be shown, the level of the water is slowly falling, from the water being pumped out from the chalk at a rate in excess of that coming in by percolation, it might have been expected that the salinity would become less; but, judging from our present knowledge, the water will retain its characteristics for an indefinite period.

Several attempts have been made to explain the abnormal characters of the waters under consideration, the most popular, perhaps, being the suggestion of infiltration of sea-water (see Braithwaite, Proceedings Institute Civil Engineers, xiv., p. 507). The hypothesis, however, is clearly untenable, and does not account for the known facts. If such infiltration were possible in Essex, it hardly could be so in London, and still less at Wokingham. Further, the chalk is full of water under greater hydrostatic pressure from the hills north and south than from the bare chalk at Erith in the tidal river, and, so far from sea-water entering there, it is well known that strong springs of fresh water discharge from the chalk into the river in that 


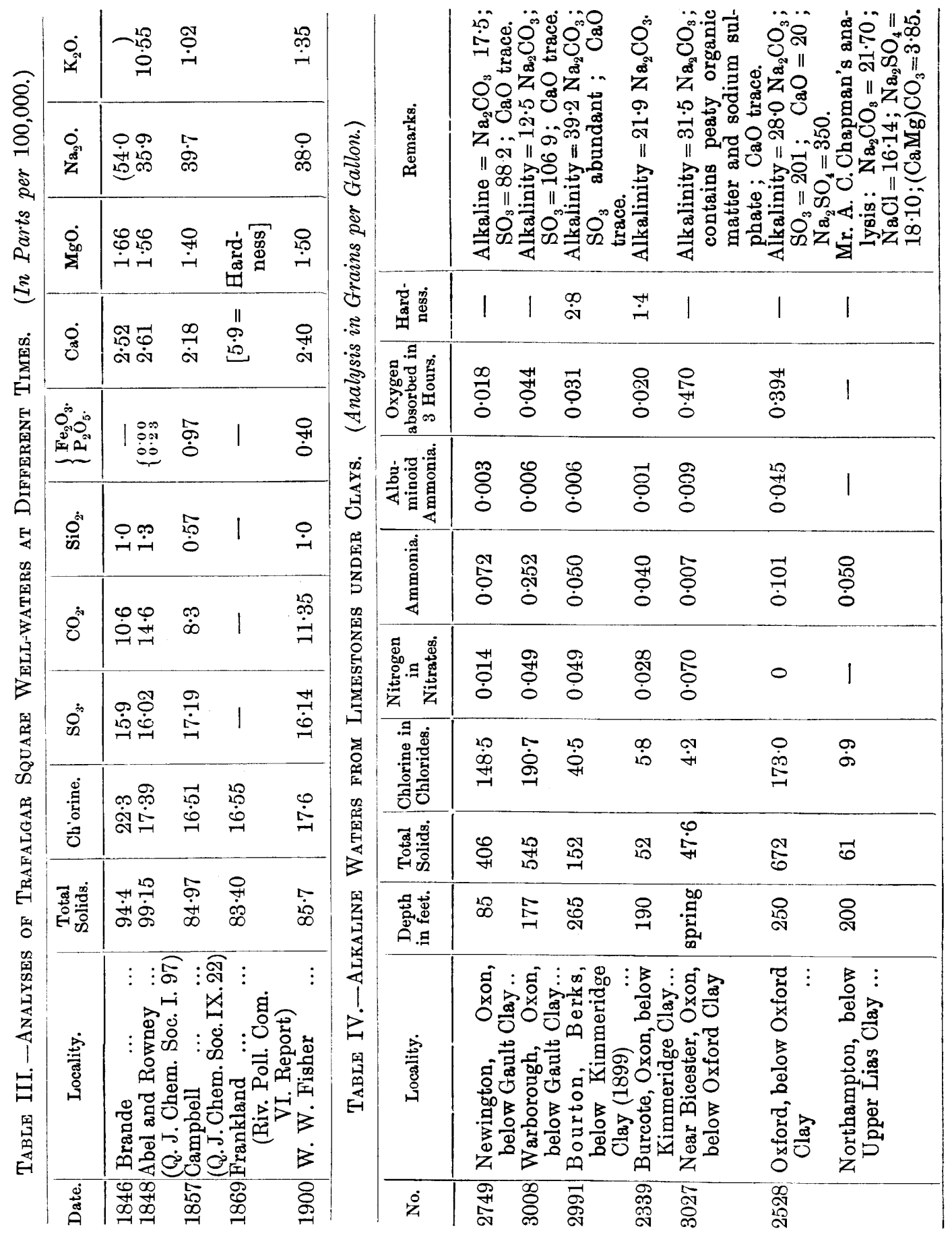


locality. On chemical grounds, too, it is clear that no mixture of sea-water with normal chalk-water could resemble our saline chalk supplies, since the relative amounts of chlorides and sulphates are entirely different, and such a mixture could not contain free alkaline carbonate. Further, there is no relation between the amount of salinity of any waters of this class and the distance of the well from saltwater or the sea.

Dugald Campbell also argued against the sea-water theory (Amer. Journ. Chem. Soc., ix., p. 22), and came to the conclusion that the origin of the water is not the ordinary chalk stratum, but it comes from a separate and independent source, and suggests the tertiary beds above as the source of the saline matters.

In an account of Guy's Hospital well, Professor Odling (1860), who discussed this question, favoured the explanation that the most probable source of the carbonated alkali is to be found in the decomposition of alkaline silicates, chiefly silicate of soda existing in the strata above the chalk. Indeed, he showed that readily decomposed silicate of soda was an actual constituent of the sand stratum overlying the chalk obtained from the borings at Guy's Hospital well. But he makes also the important point that in a well at Vauxhall the chalk-water contains more carbonate of soda than the water from the sand above, and less sulphate of soda than the latter. There is much to be said in favour of this view, but it is not entirely conclusive, since the exposed tertiary beds do not yield waters of an alkaline or saline character, but only those, like the chalk, buried beneath the London clay, and subject to similar conditions.

In looking for a satisfactory explanation of this question, I have been strongly impressed by the fact that the alkaline waters are not peculiar to wells sunk through London clay, but are commonly (almost universally, I may say) met with in wells which, in the counties of Oxford, Berks, or Bucks, are sunk through clay formations into the porous limestone or other beds below. Many such instances are met with in wells sunk through gault, or Kimmeridge, or Oxford clays, and I hardly know an instance to the contrary. One or two examples have come to my knowledge of wells sunk into the porous middle lias beds between the upper and lower lias clays which yield saline and alkaline waters.

In Table IV. I have given a few examples of such waters.

We are therefore led to the conclusion that the origin of the saline matters must be sought for in the beds themselves, and that the overlying impervious clay is a necessary contributing factor in the case.

Now, in the Thames Basin London clay is a very extensive thick deposit, which, from Hungerford in Berks to the east coast of Essex, extends over a distance of 120 miles. The width in London is about thirty miles from north to south, and in Essex rather more. The north of Kent is partly covered by a long stretch of this deposit. Obviously, no water can pass downwards through this impervious layer, and the water which reaches the chalk below must enter beneath the edges of the clay, and the supply to the Trafalgar Square well comes either from the Hertfordshire chalk downs, a distance of fifteen miles underground, or those near Croydon, a distance of about nine or ten miles. Below the clay the chalk and tertiary beds are fully charged with water, and at the edge of the clay strong springs, fed by the surplus waters, break out; such waters being of the normal type of chalk supplies. Owing to the depression of the chalk in the centre, the waters have no 
natural escape open to them, and would remain indefinitely in contact with it, and even when, owing to wells being sunk, a portion is removed by pumping, it is clear that a long time is required for the underground water to travel ten or fifteen miles. The chalk itself being remarkably compact, partly owing to the pressure from above, and more perhaps to the absence of such fissures and channels as would be produced by the ordinary action of flowing water, great resistance is offered to the passage of water through it. All the conditions favour the taking up of any soluble salts by water in contact with such chalk. It may also be pointed out that uncovered chalk, being subject to percolation for ages past, has lost the greater part of the easilydissolved constituents, while the buried chalk, having no drainage outlets, has not been washed in the same way, and the soluble matters to a large extent remain.

These considerations appear sufficient to explain the increased proportion of chlorides and sulphates in such waters, and I hope to bring before the Society evidence of the progressive increase in saline constituents after an increasing length of underground passage of water through cornbrash under Oxford clay. The explanation of the presence of sodium carbonate, although a little more complicated, is essentially the same in principle. I have observed that as a fact nearly all chalk and limestone waters contain minute quantities of alkaline carbonates, which can be detected by the action on turmeric paper, and further traces of sodium carbonate are frequently present in chalk or limestone. In the underground journey the proportion of alkaline carbonate will gradually increase, and as it increases the calcium salts will diminish, until mere traces only are left. Neither chloride nor sulphate of calcium or magnesium will remain, and only limited quantities of carbonates. The amount of calcium carbonate in solution will ultimately depend on the amounts of carbonic acid in the water available as a solvent, so that some of the alkaline chalk waters are harder than others for this reason. In support of this view, I have examined specimens of chalk from a boring made some years ago in the Tottenham Court Road, one from a depth of 500 feet, the other from 800 feet. The cores are in the Geological Department of the University Museum, and I am indebted to the kindness of Professor Sollas for some fragments.

Both specimens contained distinct traces of alkaline carbonate, sulphate and chloride, and when extracted with redistilled water in a platinum vessel gave distinct reactions with turmeric paper. After evaporation the residue was redissolved and filtered, and the amount of sodium carbonate estimated by titration with decinormal acid was 0.03 per cent. of the weight of the chalk. The chalk from 800 feet deep was sufficiently alkaline to affect moist turmeric paper when a little of the powder was placed upon it.

An analysis of the sample of chalk from a depth of 500 feet gave the following results :

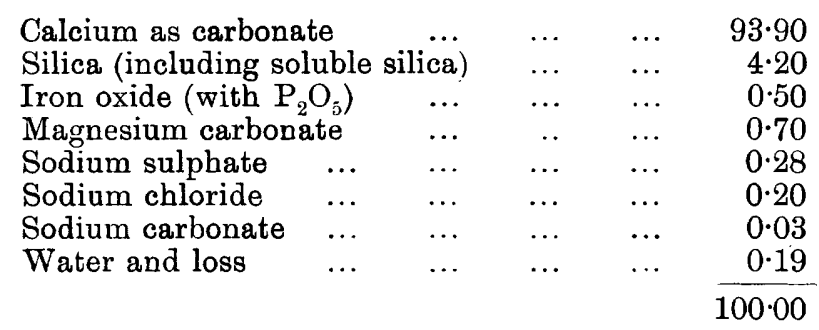


Note.-It has been shown by Way (Journ. Royal Agric. Soc., vol. xii., p. 544) that the lower chalk contains considerable amounts of silica and traces of alkaline salts.

Another specimen from a depth of 800 feet yielded alkaline carbonate in the proportion of 0.05 per cent.

The level of the water in the chalk wells below London is gradually sinking, and the Royal Commission on Metropolitan Water-supply, 1893, collected information as to the condition of many such wells (Report, Appendix, C. 4, p. 157). The depth of the Trafalgar Square well was then given as 384 feet, of which 241 feet was above the chalk, and 143 feet in the chalk. The water-level in October, 1900, was 174 feet from the surface, which is still 67 feet above the top of the chalk. The levels at various dates, according to the above report, which was prepared by Mr. A. R. Binnie, the Engineer to the London County Council, are as under : 1847, $-58 \cdot 1$ below Ordnance datum; in $1878,-83.35$; in $1888,-100 \cdot 68$; in $1891,-108 \cdot 7$; in $1900,-117 \cdot 1$. Mr. Westcott, the Engineer-in-charge, informs me that the water does not appear to fall so fast recently, but it would appear that the level sinks about 1 foot per annum. The water clearly cannot filter or travel through the chalk for so great a distance as fast as it is being removed by pumping, and in the future possibly the level will be still further reduced.

\section{Discussion.}

Mr. DibDin said that the question of variations in the quality of water obtained from certain deep wells in London had been one which had exercised the minds of all water analysts, who had hitherto generally been content to accept the explanation of Mr. Dugald Campbell-that the alkalinity of these waters was due to the solution of salts in the Thanet sands. But, if that explanation were correct, he (Mr. Dibdin) could not understand why the solution should not be much greater than was generally the case. He thought that the explanation suggested by Mr. Fisher, namely, the gradual solution of the soluble salts in the chalk during the progress of the water in its filtration through the chalk from the outside areas, was altogether far more reasonable. He would have been glad if Mr. Fisher had been able to give a few further analyses of waters drawing their supply from the Thanet sand. Any moderate variations that might be found in such waters would not in the slightest degree vitiate Mr. Fisher's argument, but would show how widespread was the variation in the quantity and character of their mineral constituents. There was another well close to that at Trafalgar Square, namely, in St. James's Park, of almost identical character; and on the south side of the Thames there were several wells yielding supplies of a similar character; while further down the Thames waters occurred which appeared to be mixtures of these soft alkaline waters with the hard water.

Mr. Richmond said that he had recently examined a sample of water from Bourton, near Swindon, which he believed to be from practically the same source as the one from that neighbourhood referred to by $\mathrm{Mr}$. Fisher. There was a supply of a similar character near Shrivenham Station, but in that case the well was only a few feet deep; and on the other side of the Great Western Railway, about a mile and a half away, where the ground rose slightly, he had found the same water from 
a well between 50 and 60 feet deep. On the other side of Swindon, three or four miles away, where the ground rose again, practically the same water occurred, the well in this case being about 100 feet deep. In all cases there was a large quantity of sodium sulphate, and the water was always alkaline. He had found, however, in going from Bourton to Swindon that there was a slight change in the water, the chlorine becoming less and less as one went further west. The chlorine in the Bourton water was about the same as that in Mr. Fisher's sample; but on the other side of Swindon, although the sulphuric acid kept fairly constant, the chlorine fell to about 22 grains per gallon.

Mr. W. T. Burgess said that in some cases the alkalinity as determined by direct titration would include a certain quantity of carbonate of lime. In order to estimate the alkalinity of water, it had been his practice for a long time, in the case of waters containing carbonate of soda, to. evaporate to dryness, extract with boiling water, and determine the alkalinity of the filtrate.

Mr. BLount said that, before one could accept so revolutionary a hypothesis as that which had been put forward as to the cause of the alkalinity of these waters, one must be quite sure of the data upon which it was founded, and he would suggest that Mr. Fisher would add greatly to the value of the paper if he would state with precision the exact methods of analysis he preferred to employ. In particular, he would ask that the method used for determining the alkalinity should be specifically stated, and also the data on which the author had been led to assume that a given water contained so much carbonate of any sort. In his own practice in water analysis, whenever a doubtful case occurred, he found that any titration method was to be put aside, the only satisfactory method in such cases being to evaporate nearly to dryness and determine the carbonic acid gravimetrically, as one would do in the case of chalk. The assumption that the alkalinity, however carefully determined, really represented the carbonic acid present in the water, and was a proper basis on which to calculate the carbonates of the mineral constituents, was apt, he thought, to lead to erroneous conclusions. The determination of each mineral constituent by some method that was quite irrefutable was the only means, not merely of arriving at a correct analysis of a water, but also of founding satisfactorily such a very interesting and comprehensive hypothesis as that referred to.

Mr. HeHNER said that it was often difficult to distinguish between the alkalinity produced by sodium carbonate or calcium carbonate and the alkalinity produced by magnesium salts. The waters now under consideration, however, contained rather small quantities of magnesium and calcium, so that the alkalinity would not be much affected by these, but would be due practically to sodium carbonate. The question of the presence of sodium carbonate in chalk was a very interesting one. Chalk was a marine deposit, and the sea certainly contained no sodium carbonate, because it contained large quantities of magnesium chloride, and the two were incompatible. Consequently, the chalk originally was not an alkaline deposit in the sense of containing sodium carbonate, and the question as to how it became alkaline was a difficult one to answer. Anybody who had looked at a chalk cliff on the South Coast must have noticed the manner in which the alternating deposits of chalk and flint occurred therein. He had discussed the subject with many geologists, 
but had never been able to obtain a feasible explanation of the fact that there occurred in the chalk at every 15 or 18 inches a well-defined layer of flint, then a layer of chalk without any flint, and so on. He did not think it would satisfy anyone to be told that during a certain era there was a deposit of chalk, that then the circumstances became such that foraminifera became less abundant and sponges predominated, these again dying out and giving place to a deposit of chalk. He had always thought that, in addition to the action of living organisms, chemical action must have played a considerable part in producing the alternation of deposits, and it was quite obvious from Mr. Fisher's observations that a chemical alteration had taken place in the chalk. Chalk contained appreciable quantities of silicates, and silicates were readily dissolved, but silica was, on the other hand, readily deposited from water. Rainwater percolating through the soil becomes saturated with silica, which readily deposits again round nuclei (spicules of sponge) and flint forms. Supposing that the chalk also contained sodium salts, then it was probable that, with water containing carbonic acid, decomposition of the silicates would take place with the formation of sodium silicate, and that through the action of this on the calcium carbonate sodium carbonate might be formed. He had always attributed the alkalinity of the water from the chalk below the London clay to the Thanet sand, or possibly to the greensand. But the explanation suggested by Mr. Fisher would be far more satisfactory if it were confirmed by an examination of the waters from other chalk districts where similar conditions existed. No doubt in this or other countries there were many beds similarly situated.

Mr. FAIRLEY said that in certain parts of Yorkshire alkaline waters occurred very frequently, especially in the neighbourhood of coal formations, and under certain portions of the millstone grit and other formations. He was not sure whether such waters always occurred in connection with beds of clay, but the quantity of carbonate of soda which they contained was sometimes very considerable. The question had sometimes occurred to him whether this sodium carbonate might have been formed from sodium salts in some way similar or analogous to that in which sodium nitrate was formed in the nitrate beds of Chili or sodium carbonate in the natron beds of Egypt, where organic matter played some part in the changing of what was no doubt originally sodium chloride into sodium nitrate in some cases, and into sodium carbonate in others. He thought that in the case of waters like those referred to it would be interesting to look for other alkaline bases. In the colliery waters of the North of England lithia was nearly always present, though it had been reported in only a few instances. Its presence was probably attributable to the decomposition of lithia mica occurring in the coal measures. In examining water for lithia, it was impossible to obtain satisfactory results without subjecting the water to a very careful process of concentration as a preliminary to spectroscopic examination. The leading principle should be to use only such reagents, and a minimum quantity of them, as would introduce the least possible risk in the analysis by introducing the substance that was being sought for. In the case of a water containing lithium, just sufficient barium hydrate would be added to precipitate all the alkaline earth metals, with as little excess as possible; and the residue obtained, after elimination of the excess of barium, treated with a mixture of absolute alcohol and ether. On evaporation a 
residue was obtained, frequently deliquescent after exposure, which showed the characteristic lithium bands very distinctly, when such bands could not be seen by direct spectroscopic examination of the solid residue.

Mr. BLount said that he could quite confirm Mr. Fairley's remarks in reference to lithia. Lithia was a very common constituent of natural water, in almost any sample of which he would undertake to find it by the method described by Mr. Fairley.

Mr. Chapman said that in the determination of alkaline carbonates by evaporating to dryness and extracting with water it was necessary, in the case of waters containing appreciable quantities of magnesium salts, to take care that the washing was not carried too far, or the results obtained would be too high, owing to the distinct solubility of magnesium carbonate. With regard to the suggestion that carbonate of soda could not coexist in water with lime salts, if bicarbonate of soda solution were added to water containing several grains per gallon of sulphate of lime or sulphate of magnesia, the water remained perfectly bright. The conclusion he had come to was that those who systematically made complete mineral analyses of water observed a good many facts not commonly stated in the text-books. He preferred to express the results of such analyses, not in terms of the water, but in terms of the residue. $\mathrm{He}$ would like to ask Mr. Fisher whether he had formed any hypothesis to explain the presence of what was an extremely common constituent of pure waters of the class referred to, namely, saline ammonia in quantities, which in any other waters would be held to indicate pretty extensive pollution. He was not quite at one with Mr. Fisher in thinking that these waters rarely contained any appreciable quantity of lime or magnesia. In his experience, waters from similar beds in other parts of the country, while they contained often not more than 2 or 3 grains per gallon of the carbonates of lime and magnesia, sometimes contained as much as 8 or 10 grains per gallon (but not often more) of calcium carbonate.

Mr. C. A. MitcheLL inquired at what temperature the total solids were dried. It was rather difficult to expel all moisture at the ordinary temperature of the waterbath, while at a higher temperature magnesium chloride would be decomposed.

Mr. Fisher said that the total solids were dried on the water-bath.

The President (Dr. Voelcker) said that, to sum up Mr. Fisher's conclusions, they were to the effect that, in the case of the bare chalk, the alkaline carbonates were practically washed out entirely; but in the case of the chalk being covered by clay there was not such a thorough washing out, carbonate of soda being present to a very much larger extent than carbonate oi lime, the carbonate of soda being originally an integral constituent of the chalk. This matter, of course, had to be looked at from several points of view and in regard to many different kinds of water. Analysts had been in the habit of saying that waters drawn from the chalk, but which were found to contain only a little lime, were to be regarded as somewhat abnormal, the explanation usually suggested being that there was some infiltration from the sea, and that chemical changes took place which resulted in the formation of carbonate of soda. He had before him some analyses of waters which would very well compare with the water which Mr. Fisher had referred to, namely, those of two supplies from deep artesian wells, situated respectively at the Royal Hotel, near Blackfriars Bridge, and 
in Stamford Street, near Waterloo Station. These waters, which he had analysed at different times, contained 50 grains of total solids per gallon, only 1 or 2 grains of lime, about $\frac{1}{2}$ grain of magnesia, and 18 to 20 grains of carbonate of soda, together with large amounts of sulphate of soda; these results would lead one to similar conclusions to those which Mr. Fisher had arrived at. But there were other cases which did not quite bear this out, and he agreed with Mr. Chapman that there was not sufficient evidence of the non-existence of alkaline carbonates and lime salts together. In the case of a water from Newington, London, containing 86 grains of total solids per gallon, there were over 15 grains of lime per gallon, with large quantities of alkaline carbonates and alkaline sulphates as well. In some districts of Yorkshire, near Malton, for example, there were limited areas where deposits of carbonate of soda occurred, and the waters from the chalk in those neighbourhoods, although there was no overlying clay, frequently contained as much as 150 grains per gallon of carbonate of soda. He had made inquiries in the neighbourhood, and of geological authorities, but had never been able to find any exact records of the occurrence of these deposits or any satisfactory explanation of their presence.

Mr. DibDin thought that probably biology would afford some clue to the means by which the carbonate of soda was produced. When the chalk was deposited it originally contained a certain quantity of organic matter derived from marine organisms, and it seemed quite possible that, as the result of the microbic action that would take place during the infiltration of an aerated water through the chalk, the carbon of this organic matter had become converted into carbonic acid, and under these bacterial conditions it might have been that some of the original sulphate of soda underwent change, resulting in the formation of sulphate of lime and carbonate of soda.

Mr. Fisher said that he had been thinking over this matter for years, and had rejected various explanations, until he obtained the direct evidence of the presence of carbonate of soda in the chalk, which seemed to decide the question. He had come to the conclusion that such was the probable explanation before he was able to obtain practical evidence of it. He hoped to be able to get evidence that the limestones in the other beds also contained free alkaline carbonates, which he thought would add to the strength of the position. What in the tables he had termed " alkalinity" represented all the carbonates as carbonate of soda. The figures give some information as to the relative alkalinity of the samples. A hundred c.c. of ordinary chalk-water generally neutralized about 5 c.c. of decinormal acid, but some of these samples neutralized 7, 8, 9 or 10 c.c., which afforded an idea of the amounts of alkaline material present, translated from decinormal acid to carbonate of soda. He was quite familiar with the district referred to by Mr. Richmond. The gault clay which occurred in the neighbourhood, and which varied in width from two to four miles, was a great difficulty in the way of getting proper water. A supply by gravitation was difficult owing to the distance from the outcrop of the chalk and the greensand, while if the clay were pierced the water obtained was extremely saline. The water from a deep well at Swindon was so saline that as it carne down the Thames, at times, it affected the chlorine in the Oxford water-supply. This saline water had been traced by him in the Thames up to Lecblade, and from thence to Swindon by 
Mr. Groves. On the 1 inch to the mile geological Ordnance map it would be seen that there was good reason for the variations in the quality of the water coming from below the gault. In some places the collecting-ground was large, and consisted to a considerable extent of exposed beds of coral rag, and the water came down gradually beneath the hills. In other places the Oxford clay covered the porous collectingground, and there was only a very narrow strip of pervious rock which could get any water at all. Shrivenham Station was just on the edge of the gault, and a little further north the coral rag was exposed, and there no excess of saline matter was to be observed. If the explanation were correct as to the cause of the alkalinity, it ought to apply to any similar bed of chalk below the London clay. There was such a bed of London clay in the southern part of Hampshire, near the New Forest, on both sides of which the chalk downs rose to a considerable height, and he hoped to have an opportunity of examining a sample from this locality. All these saline waters contained exceptional quantities of ammonia, and some contained considerable quantities of organic matter. At Marsh Gibbon, where the water flowed out of a borehole, it came out quite brown, from the quantity of organic matter dissolved in passing under the ground for three miles; that water contained also a notable quantity of free ammonia. Where ammonia was present in these waters there was very seldom any quantity of nitrates. The question of the solubility of calcium carbonate in waters containing an excess of free ammonia was dependent to some extent upon the proportion of carbonic acid present. In a soda-water made from a hard water considerable quantities of carbonate of lime would be found in solution as well as carbonate of soda. It was generally the case that those waters which were alkaline contained very small proportions of carbonate of lime, though he was not certain as to how the lime might have disappeared. Frequently there was only so much lime in solution as would dissolve per se as calcium carbonate. 